LA-UR $-82-1092$

$$
\text { CONF-800447--2 }
$$

LA-IJR- -82-1092

DE82 014042 .

TITLE: COORDINATE SYSTEM CONTROL: ADAPTIVE MESHES
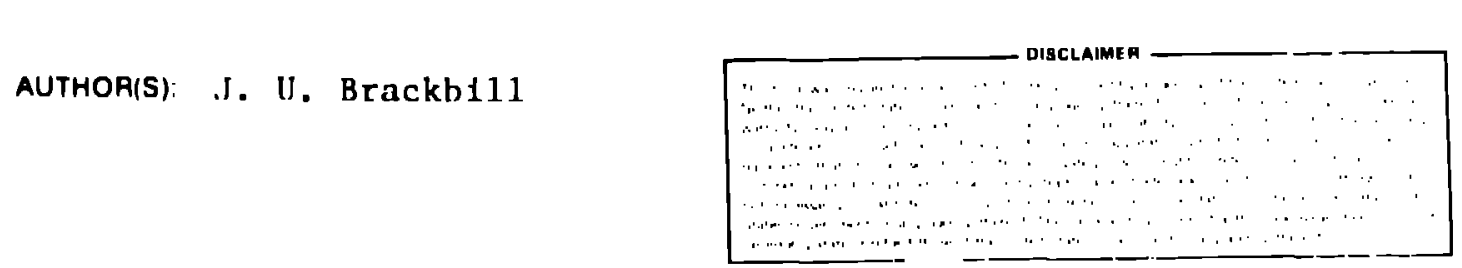

SUgMitted to: Numericial fieneratlon of Curvillneilr coordfunte systems Sympostum, Nassliv ll1e, 'TN, AprIJ 1982

\title{
MOTICE 、
}

PORTIONS OF TIIIS MFI T!IT ARF ILLEGIBLE.

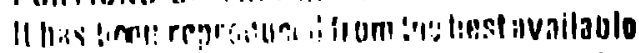

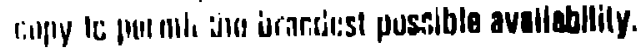

MN ONLY

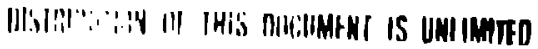




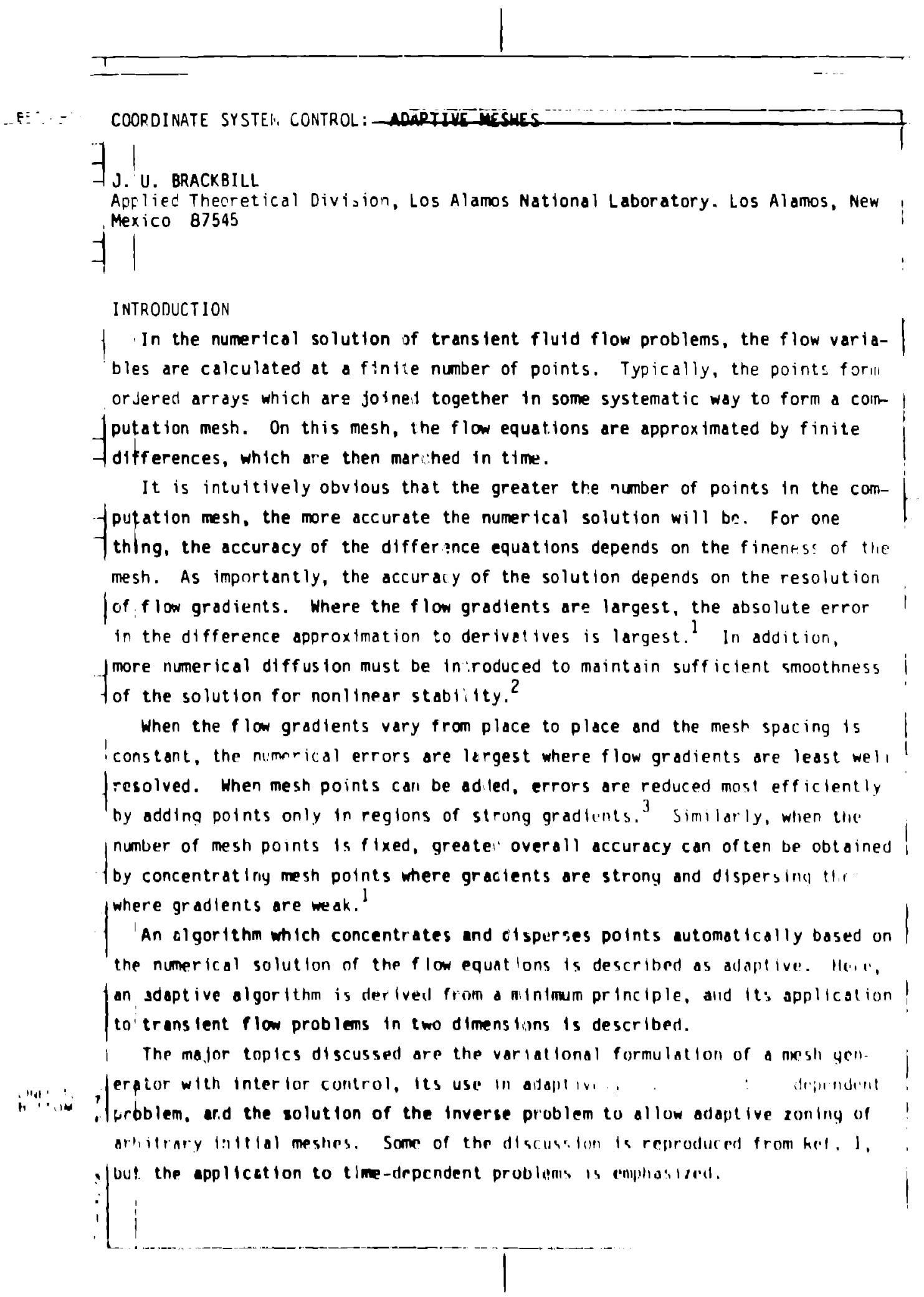


D5 9 HEP TARIATIONAL FORALLAT ION OF THE ME SIL GEAERATOF

f For the solution of finite difierence equations on a computation mesh, the tata is typically stored in ordered arrays of numbers, $0(i, j)$ in which the jindices $1-1, \ldots, M ; j-1, \ldots, N$, give not only the location of the data fin computer memory, but also the physical relationship betwen the data at one vertex $\underline{x}(i, j)$ and ariother, $\underline{x}\left(i^{\prime}, j^{\prime}\right)$.

In folmulating the mesh generator problem mathematically, it is useful to vidu the mesh, whose vertices are $x(1, j)$, as the image of a rapping $x(\xi, n)$ in which the polnts corresponding to integer values of the natural coordinates, $F$ and $n$, are the mesh vertices. The image of the mesh in natural coordinates is ta unform, rectilinear mesh with mesh spacing $\Delta \xi=\Delta n=1$. A mesh generator determines the mapping $\underset{x}{x}(\xi, n)$.

Obviously, the diffarential properties of the mapping are reflected in the praperties of the computation mesh. For example, $\left[(\partial x / \partial \xi)^{2}+(\partial y / \partial \xi)^{2}\right]^{i / 2}$ along a level curve of $n$ is related to mesu spacing betweer vertices with the same index $j$. Similarly, the volume of computational cells is relateo to the Jacobian, $J$, of the mapping.

$$
J=\frac{\partial x}{\partial t} \frac{\partial y}{\partial n}-\frac{\partial x}{\partial n} \frac{\partial y}{\partial t},
$$

fand the orthogondity of the mesh is related to the scalar, VE, : in, mli, i, i.. zero when conjugate lines of the mesh are orthoyural.

Integrals nver the computation mesh con be writtan which indasurc these piaperties of the mapping. The glubal smoothness of the mapping (the varia$t$ ton in mesh spacing along level curves of $($ and $n$ ) is masured by (he inte. gral.

$I .-\int_{D}\left[0()^{2}+(v n)^{2}\right] d v$.

the orthogonulity of the mapping is measured by,

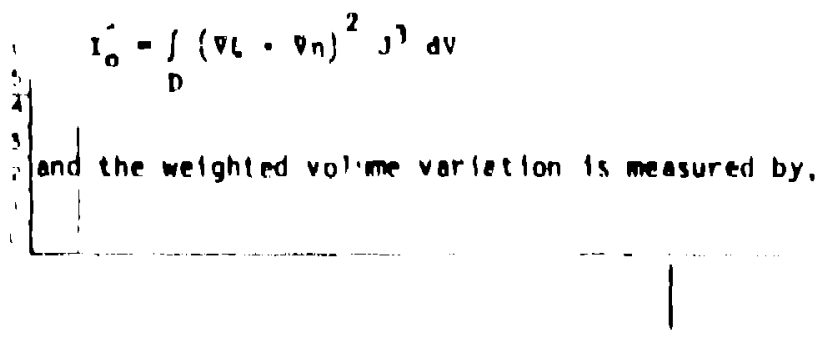




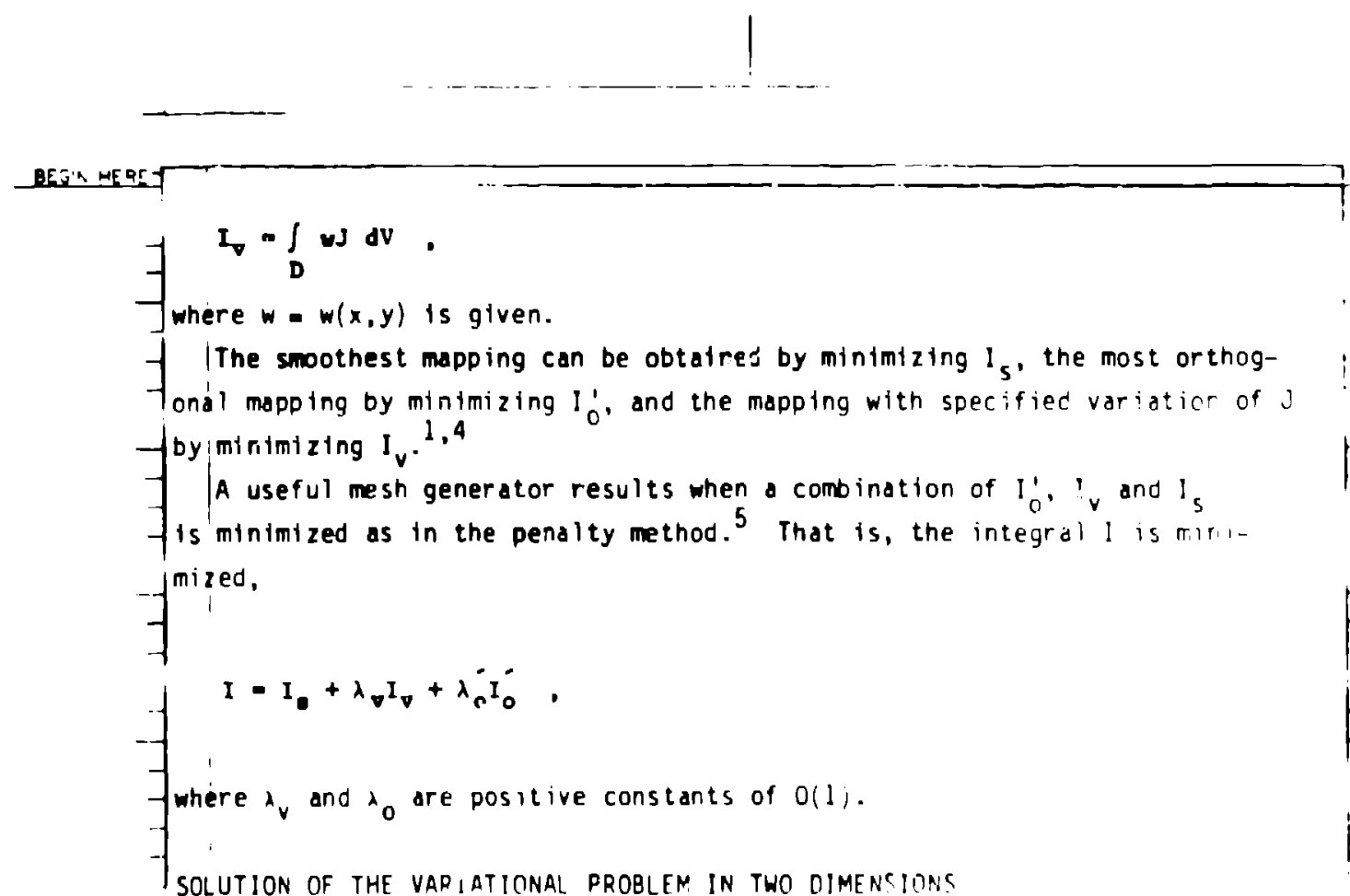

SOLUTION OF THE VARIATIONAL PROBLEM IN THO DIMENCIONS

To derive the Euler equations for the variational problen formulateci ir the fpreceeding section, $t t$ is first convenient to interchange dependent and independent variables using the relations.

$$
t_{x}=\frac{+y_{n}}{J}, \quad t_{y}=\frac{-x_{n}}{.}, \quad n_{x}=\frac{-y_{6}}{J}, \quad n_{y}=\frac{+x_{6}}{.1} .
$$

After interchanatna variahles. the smoothness measure can be wriller.

$$
\text { I. }-\int_{1}^{M} \int_{1}^{N} x \operatorname{con} \frac{\left(x_{i}^{2}+x_{n}^{2}+y_{0}^{2}+y_{n}^{2}\right)}{y} .
$$

for which the corresponding Culer equations are,

$$
\left(\frac{\partial}{\partial x}-\frac{\partial}{\delta \zeta} \frac{\partial}{\partial x_{x}}-\frac{\partial}{\partial n} \frac{\partial}{5 x_{n}}\right)\left(\frac{\left(x_{x}{ }^{2}+x_{n}{ }^{2}+y_{c}{ }^{2}+r_{n}{ }^{2}\right)}{J}\right)-n \text {. }
$$

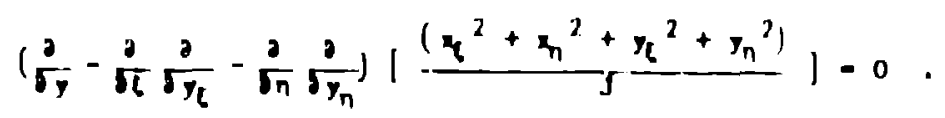


I.-.-

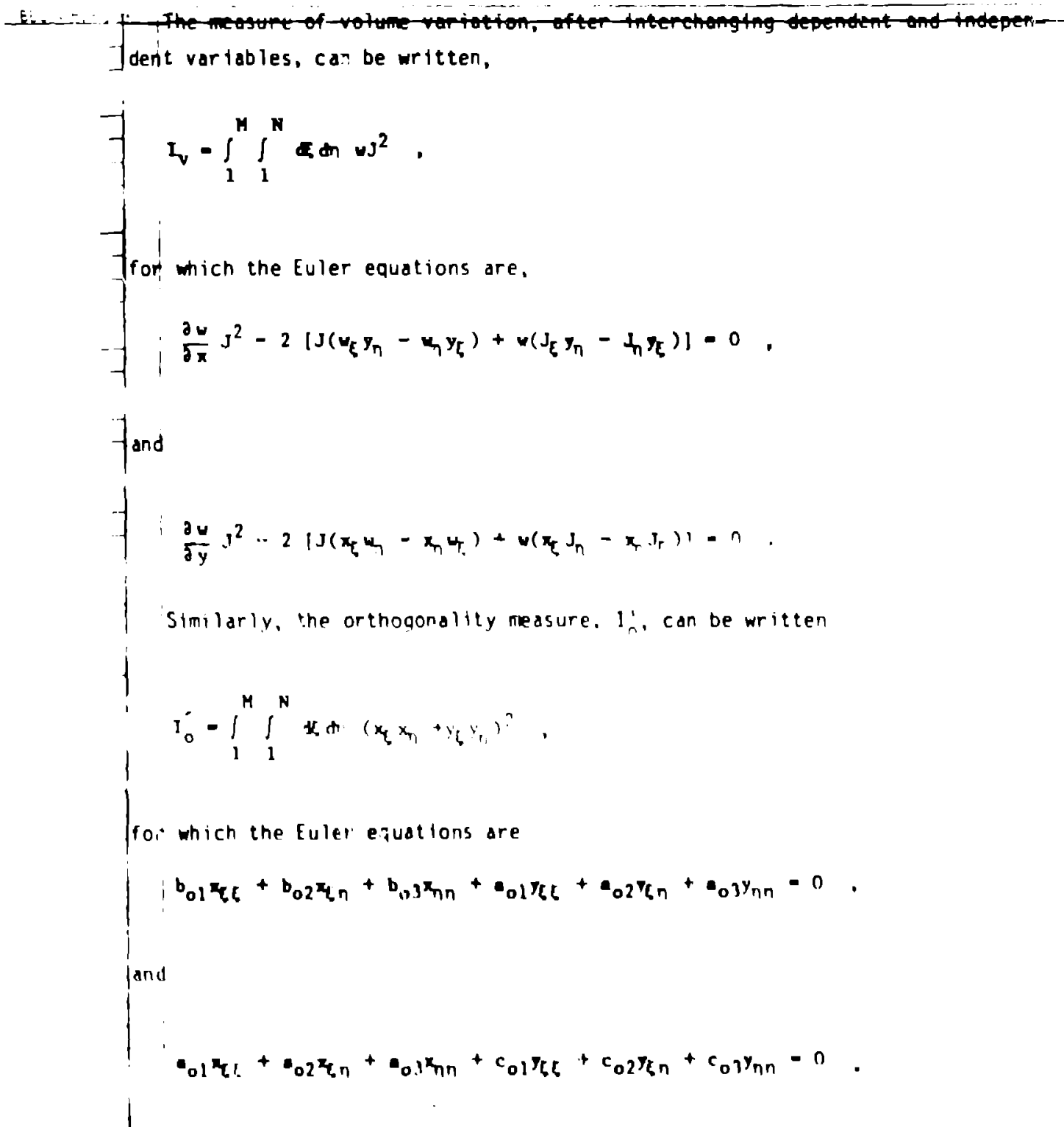

The mesh generator equations call br written in a form convenient fer combo$\therefore$ i fetation by collecting the ccefflelents of the highest derivatives nt $x$ and $y$

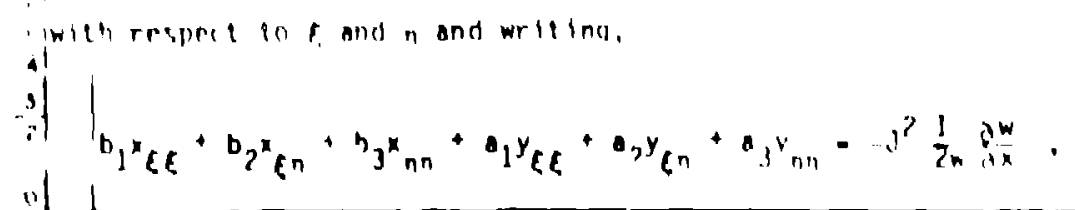




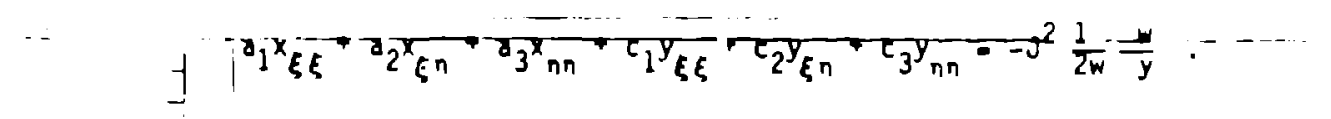

$-f$ The coefficients are reproduced here from Ref. I for compiteteriess:

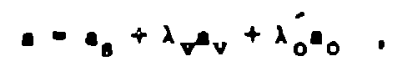

$$
\begin{aligned}
& f \quad b-b_{0}+\lambda_{0} b_{v}+\lambda_{0}^{b_{0}} b_{0}, \text { and } \\
& c=c^{a}+\lambda^{q} c^{v}+\lambda_{0}^{0} c_{0} .
\end{aligned}
$$

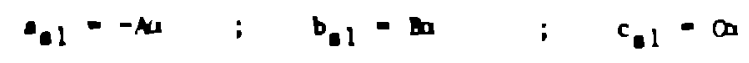

$$
\begin{aligned}
& . .2-2 A B \quad ; \quad b_{.2}--2 \triangle B \quad ; \quad c_{02}-2 C B \\
& a_{B_{3}}=-A Y \quad ; \quad b_{13}=m \quad ; \quad c_{03}=c y
\end{aligned}
$$

I where

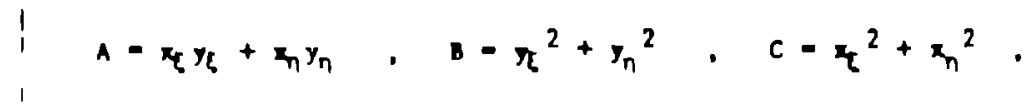

$$
\begin{aligned}
& \text { land }
\end{aligned}
$$

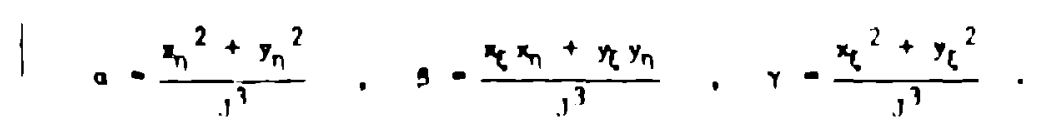

$$
\begin{aligned}
& 1 \\
& n_{v 1}, r_{1}-v_{n}{ }^{2}, c_{v 1}-x_{n}{ }^{2} \text {. }
\end{aligned}
$$

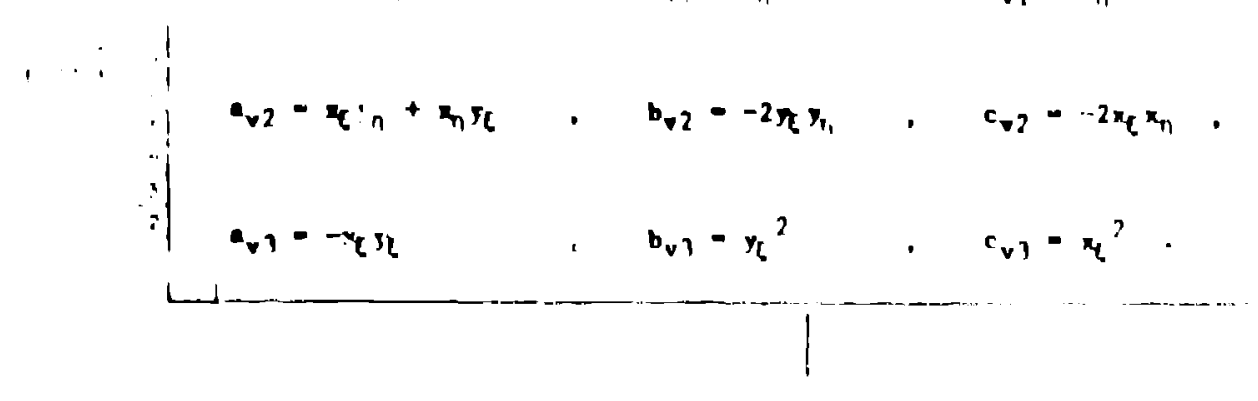


I $a_{1,1}-x_{n} y_{n} \quad, b_{01}-x_{n}^{2} \quad, c_{01}-y_{n}^{2}$,

$f c_{0} 2-y_{\xi} y_{n}+x_{n} y_{\xi}, b_{02}-2\left(2 x_{\xi} x_{\eta}+y_{\xi} y_{n}\right), c_{02}-2\left(x_{\xi} x_{n}+2 y_{\xi} y_{n}\right)$. The generator equations form a set of coupled, quasi-linear, partial differenftial equations of second order which are only slightly more complex than in the original Hinslow algorithm.

Algebraic equations at each node result from the substitution of the aififerences for derivatives. The system of equations is solved bv a lacoti iteration in which the values of $x_{i, j}$ and $y_{i, j}$ are treated as parameters. The literative solution of these equations will givo new values of $x_{i, j}$ and $y_{i, j}$ twich satisfy the Euler equations above. A more complete discussion of the numerical solution of the Euier equations is given in Refs. 1 and 6.

TTHE ADAPTIVE MES'H

By choosing on appropriately defined weight function, $w(x, y)$, the mesh generator $c$ an be made part of an algorithm to adapt a computation mesh ayriamifcally to sata generated by the solution of finite difference equations.

The weight fu'............. ar the duta in such a way that numerical jerrors are reduced. An obvious approach is t. minimize the truncation error for a particular olfference approximatioa. While this may be optimal, detaileo janalysis of a given differenice equation usually yields a very complex expression for the truncation error whose minimizatiun may have no clear corinection to the variational forms above.

However, a simpler approach yields a practical, yet useful, algorithm. As fhas becn noted already, numerical errors are reduced significantly when flow gradients are well resolved. When there are sufficient mest points in each iaradient length of the function being represented, the smoothness of the funcition assures that truncation errors and numerical diffusion necessary for nonlinear slabilily are reasonable.

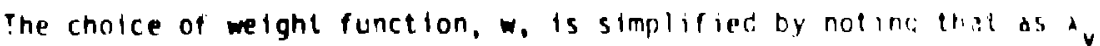
becomes large, the solution to the mesh generator can be writicn,

3) $\quad \mathrm{J}^{2}-\operatorname{cons} \mathrm{t}$.

Where 0 , the functioll being represented, is posilive, weight function with lcorrect dimensionality is given by. 


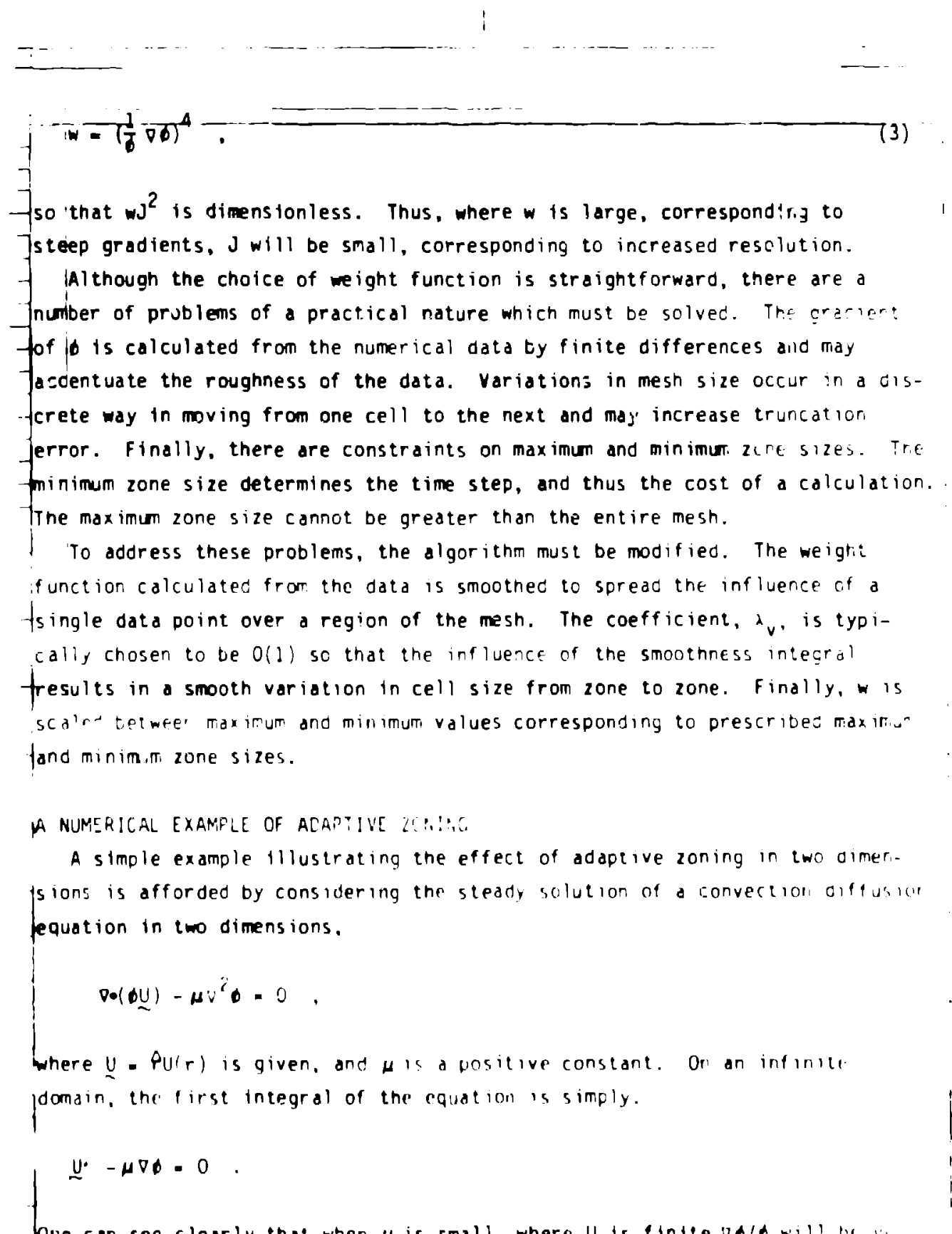

Gne can sef clearly that when $a$ ic small. where II ts finlte vold will l. 6

jlarge. Choosing U(r) to be a function which is non-zerce only in an ann. lise (") awidth or at $r_{0}$ wlll result in the formation of a boundary layer at $r_{0}$.

To demonstrate the increased accuracy of difference equations with adaptiv:" ifoning the solution is given ana ically, and the error is defilu 


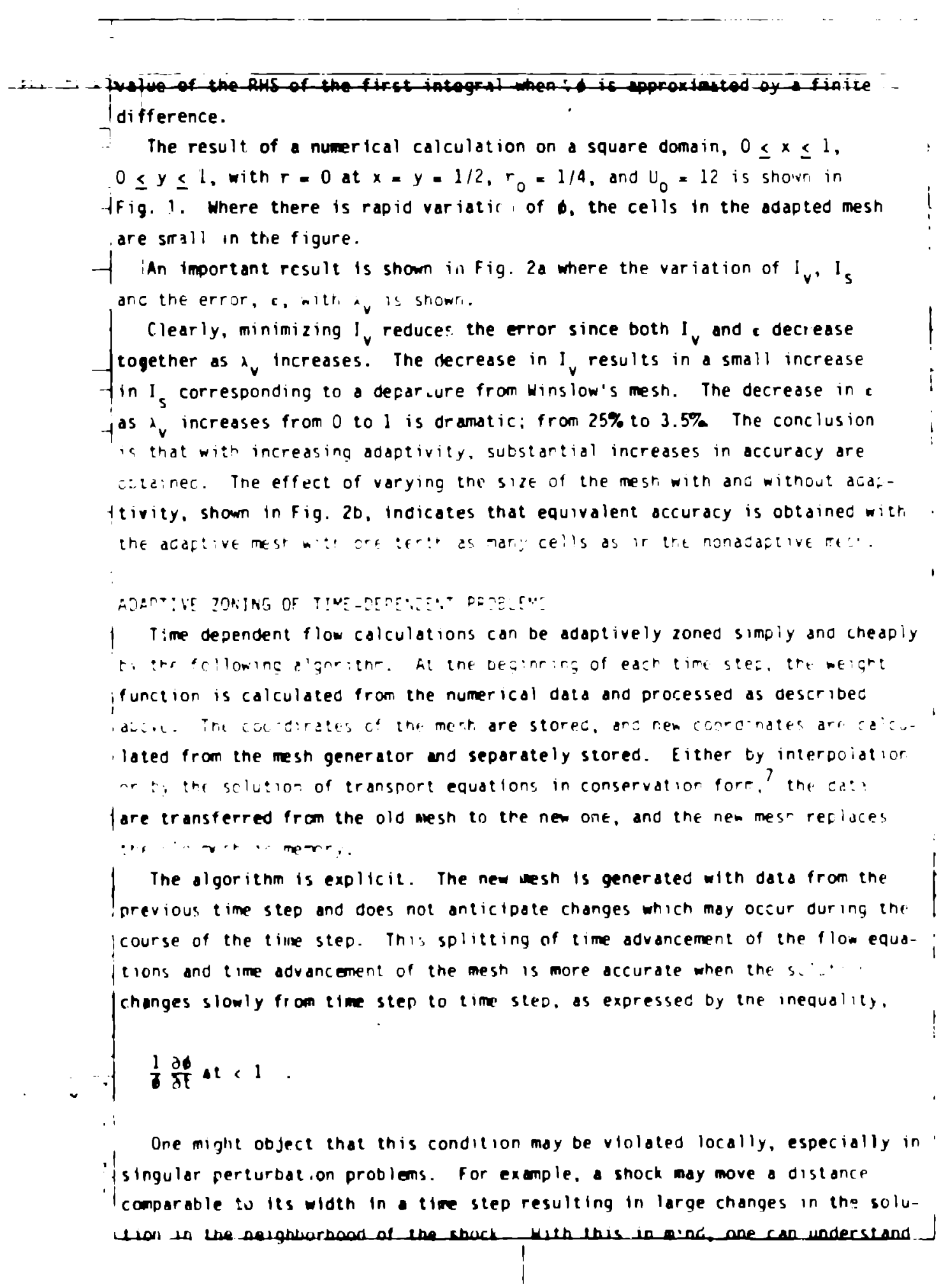




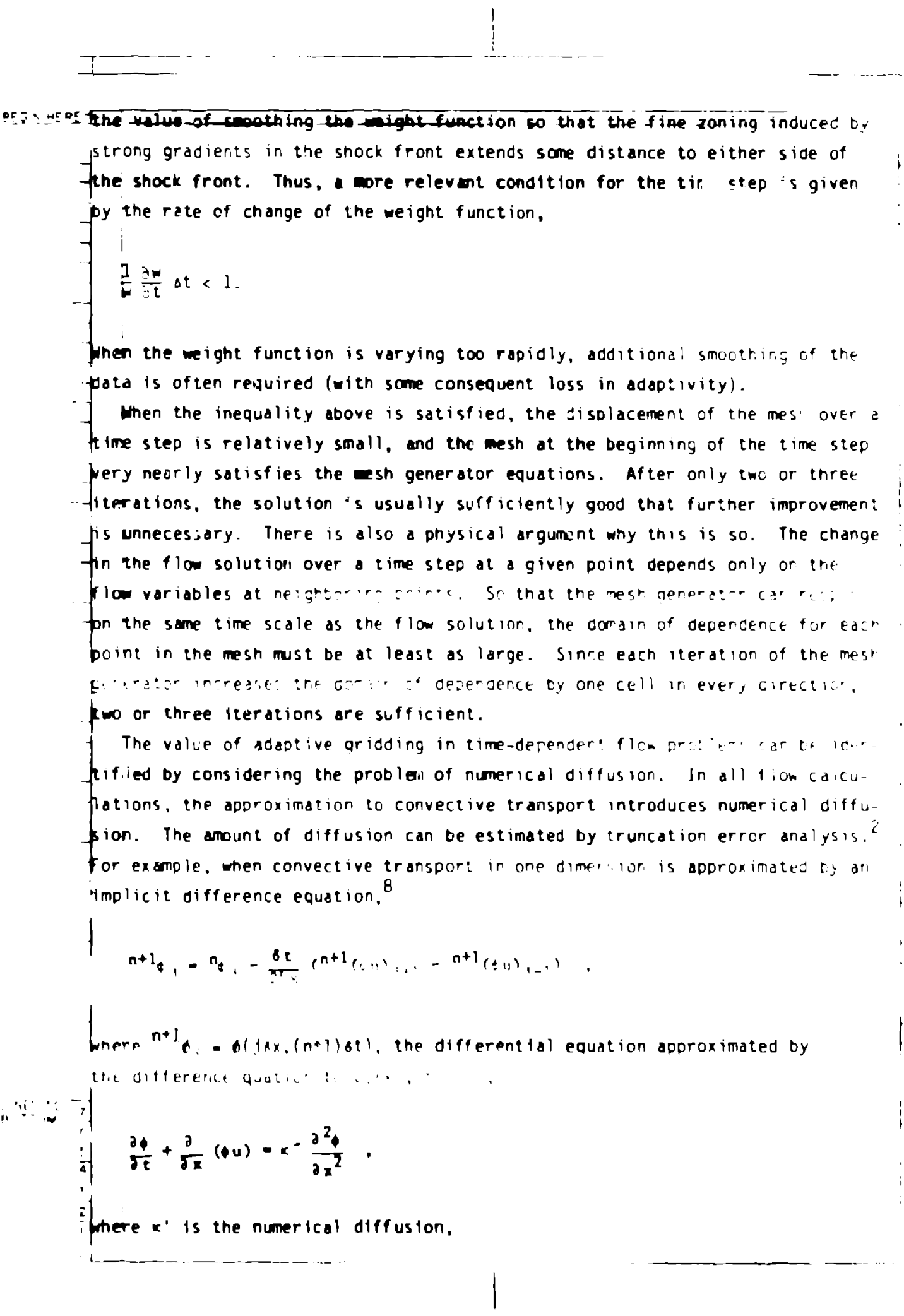




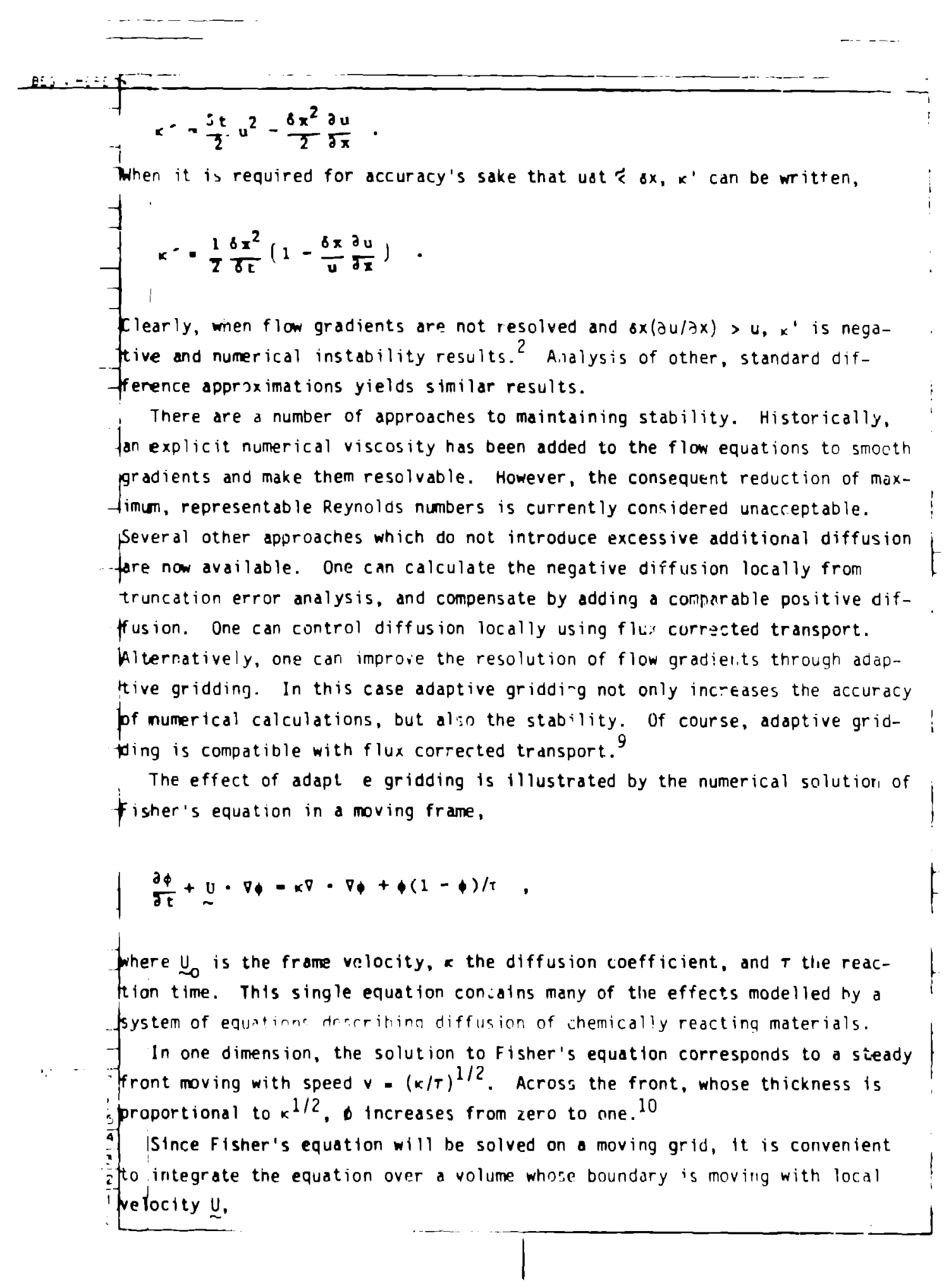




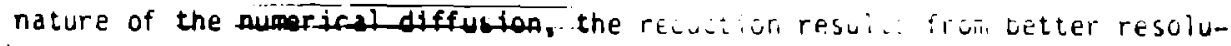
ftion of the flow gradients.

ADAPTIVITY FOR ARBITRARY MESHES: THE INVERSE PROBLEM

'To app'y adaptivity to a non-uniform mesh, one must solve the following finverse problem: consider a mesh given by the solution of the mesh generator fequations with $\lambda_{v}=0$. This mesh satisfies the generator equations with $f_{\lambda_{v}} 0$ only for some particular $w(x, y)$, winich must be calculated.

In a typical problem. one has no a prlo:i knowledge of the location of fbourdary laye s or shocks. Hiwever, the boundaries of the domain or embedded structures may be represented most conyeniently using the mesh generator with $\lambda_{v}=0$, or by a simp.le funct lond mapping $x(\xi, n), y(\xi, 7)$. To adaptively zone a calculation using this mesh as the initial mesh, one must calcuiale lut corresponding $w_{I}(x, y)$.

The weight function $w_{I}(x, y)$ can be calculated from the iuler equatic fmost conventently when they are written in a form which explicitly oisplays their dependence on $w$ and its cierivatives. This form can be derived from Eqs. (1) and (2) by collecting coeffirients of $\mu, \partial w / \partial x$ and $\partial w / 7 y$ to obtain, 1

1

$$
s_{1}+n_{1}+\lambda_{v} y^{2} j x=0
$$

dilil

$$
S_{2}+w R_{2}+a_{v} J^{2} \frac{\partial w}{\partial y}-0 .
$$

Where $S_{1}, S_{2}, K_{1}$ and $R_{2}$ ere mastly evaluated using the defintetions of the coefficients and are fuctictions of the given mesh coordinate..

These anuations are easlly integrcted along level curves of the computation jmesh. Hoting that w, anil ware gtven by the chain rule, the dirivalives c. arl ber viliten,

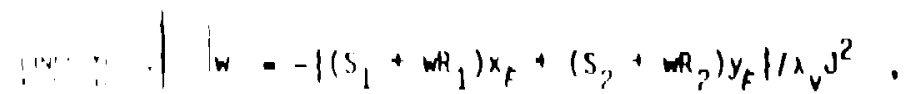

$\therefore$ init

i) $\mid w_{n}=-\left\{\left(S_{2}+m_{1}\right) x_{n}+\left(S_{2}+m_{2}\right) y_{n} \mid / A_{x} J^{2} \cdot\right.$ 


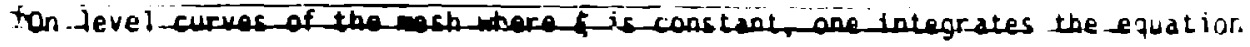
ffor $w_{n}$, and vice versa for mesh lines where $n$ is constant. So that the jresu'ting $w$ is single volued, one must require inat the difference equations f satisfy the condition,

$$
\left.\left.\right|^{\left\langle w_{n}\right.}\right\rangle-\left\langle w_{n \xi}\right\rangle=0
$$

whe.e the brackets denote difference equations.

! A simple example taken from a recent calculation of magnetic reconnection in the earth's magnetosphere is shown in Fig. 7. The mesh is generated in the fupper half plane with level curves of $E$ corresponding to nested ellipses whose feccentricity increases from zero at the center to some large value on the out-. side. In addition, the distance between ellipses increases geometrically from the center outward.

With $A_{v}+0$ and w ralculaied from Eas. (4) and (5) above, the inesh which satisftes the generator equa'ons is as shown. With $w$ equal to a constant. ithe mesh would collapse onto 'he cenir of curvature. 6

ADAPTIVE ZONING FGR MCVING BOL, DARY CALCULATIONS

In many moving boundary calculations. the ability to redistribute points along the beundary tricreases the accuracy and reliabllity of the calculatlons. for example, In the modeling the Rayleigh-Taylor Instability at the interface between two flulds reglons of large curvature may develon which requirr addi. llonal points to resolve. When the to:nl number of points along the interface is fixed, the points may be redistributed along the curve using the adaptifve me th generator.

Where the curve is parameterlzed by s, so that $x-x(s)$, y $-y(s)$ where s. $\mathbf{s}(\xi)$. the analogu. 0 : the smoothness integral along the curve may be written,

$$
l_{s}-\int F_{1}^{2} d s
$$

To alter the distributlou of polnts along the boundary, the integral.

$1_{n}-\int w s^{2} d t$

s minimiset with given helght function $w(s)$. When is is proportional to the cirvaturn 


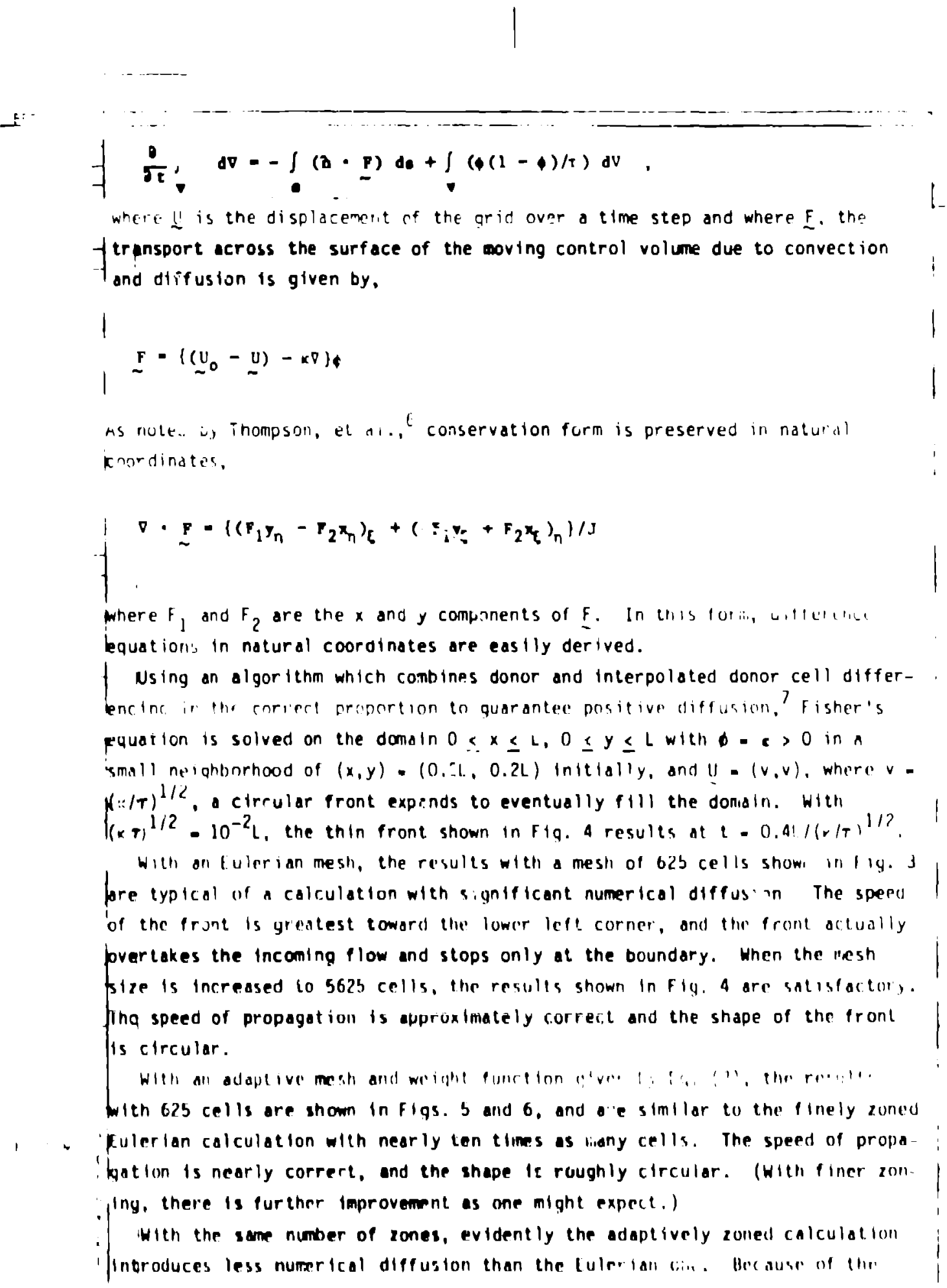




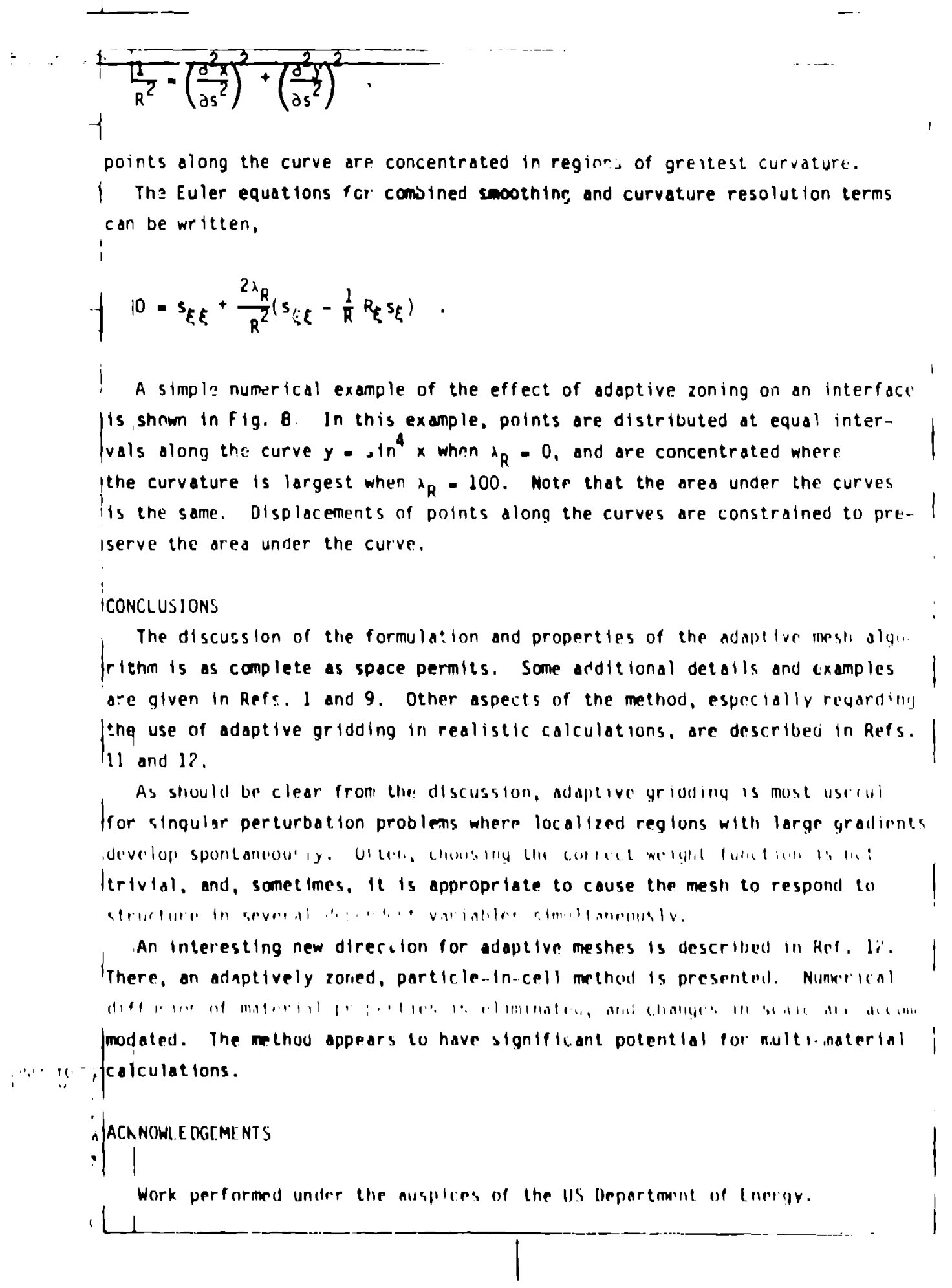


REFERENCES

D. J. U. Brackbiil and J. S. Soltzman, Adaptive Zoning for Singular Problems in Two nimens lons, U. Comp. Phys., to be published.

2. C. W. Hirt, J. Comp. Physics., 2, 339 (1906).

B. I. Babuska and W. Rheinboldt. STAM J. Num. Anal., 15 (1978).

A. M. M. YanenkJ, V. M. Kovenya, V. D. Lisejk in, V. M. Fon in, and F. V. Vorozhtsov, Prue. 6th Int'1. Conf. on Num. Meth. In Fluid Dynamics, lee ture Notes in Physics, 90, 565 (1979).

f. R. Courant, Trans. Amer. Math. Sor., 50, 40 (1941).

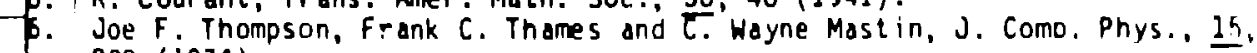
299 (1974).

D. C.W. Hirt, A. A. Amsden and J. L. Cook, J. Comp. Phys, 14, 227 (15?4).

B. J. U. Brackb1il, Meth. Comp. Phys., 16, 1 (1976).

y. J. J. Saltzman and J. Brackbilll. AppTfications and Generallzations of Vari at ional Methods for Generat ing Adapt tre Meshes, the:e proceedings.

10. J. Canosa, IBM Journal of Pesearcl, ar.d Developenent, 17, 3(1; (1973).

11. R. D. Miliroy and J. I. Brackbiil. Mumerica i Studies of a fic ic neverecu Thet a Pinch Plasma. Phys. of Fluids (to appear).

12. J. U. Brackbtll and H. M. Rupfel. A Method for Adaptively Zoned, Particle. ill-Cell Calculations in Two Dimensions, submitled J. Comp. Pliys.

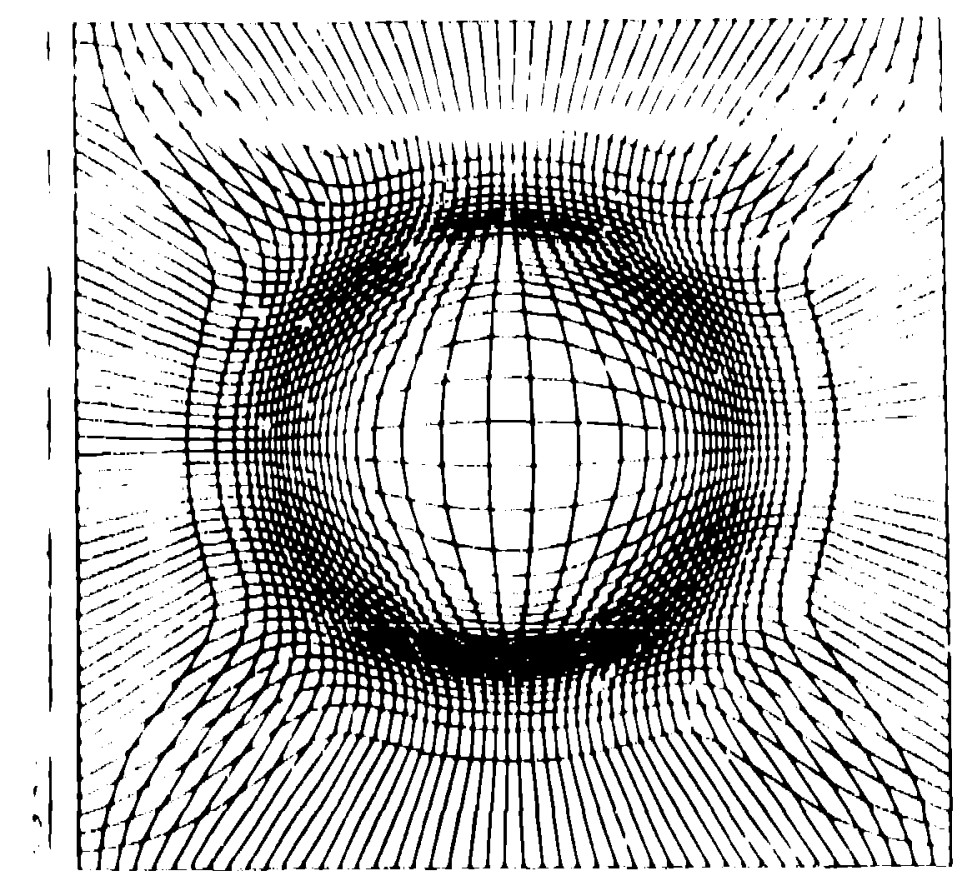

Fly. I. In the acianctive men.h. llie zones or comsen trated in an annulus - herer thrier is the quentout vartatlon In the solution. 


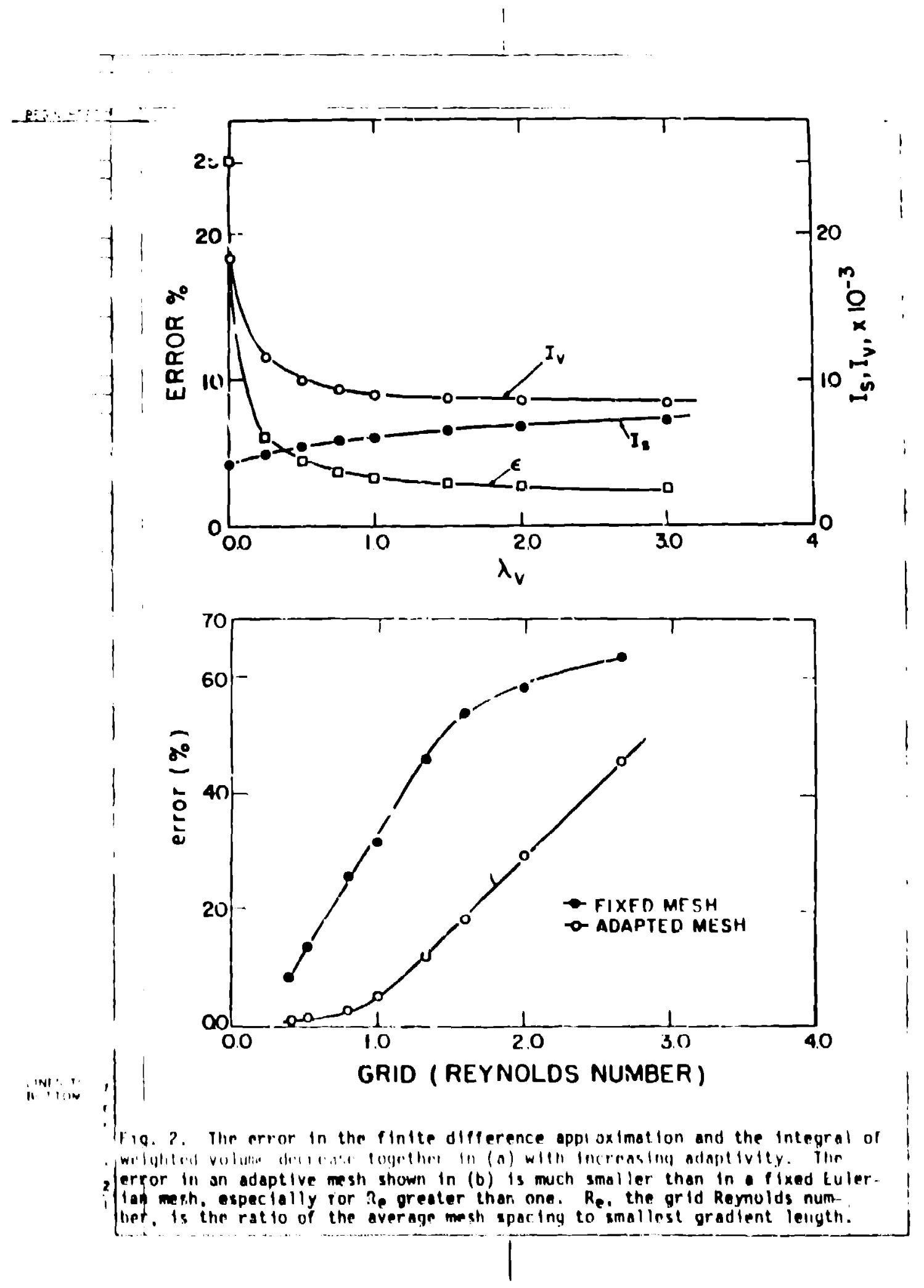




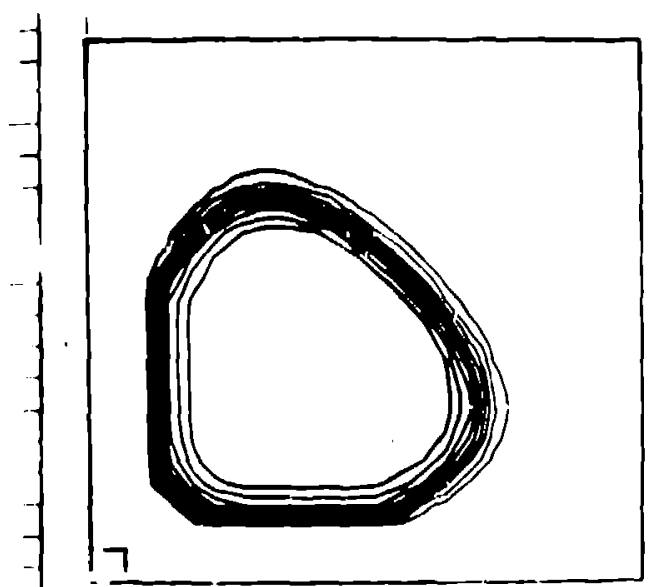

itg. 3. The solution of Fisher's equation on a 625 zone Eulerian mesh is deplcted. Contours of constarit are concentrated in the front across which o increases from 0 outside to 1 inside. The distortion of the front from the correct. circular shape is evident.

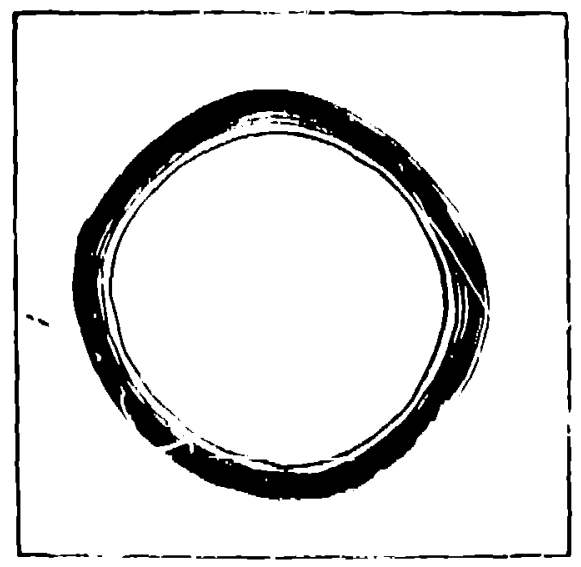

- Fiq. 5. With a 625 zonr adaplive mesth. comparable solution to nre with a \$675 cone Eulerian mesh ta oblatued. The shape is

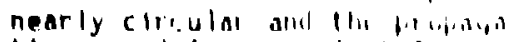
tion ripeed is approximately cor reci.

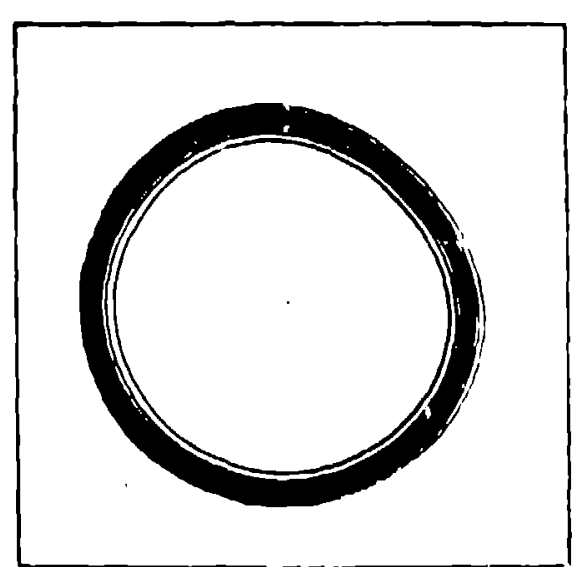

Fig. 4. With a 5625 zone Eulerlan mesh, a solution with a more circular front and correct propagation speed is obtained.

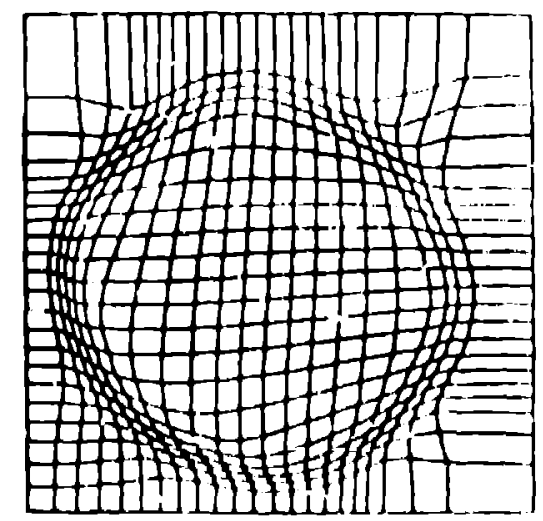

Fla. 6. The mesh corresponding to 1 lg. 5 is showr. Hote thr" concentration of zones in :he front.

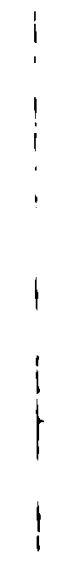

. 


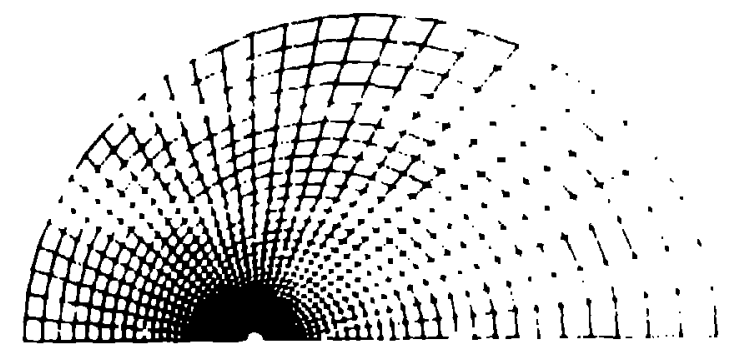

Fig. 7. A computation mesh for a simulation of reconn?ction in the earth's magnetosphere is shown. The grid results from the solution of the inserse probiem with adaptivit: implemented.

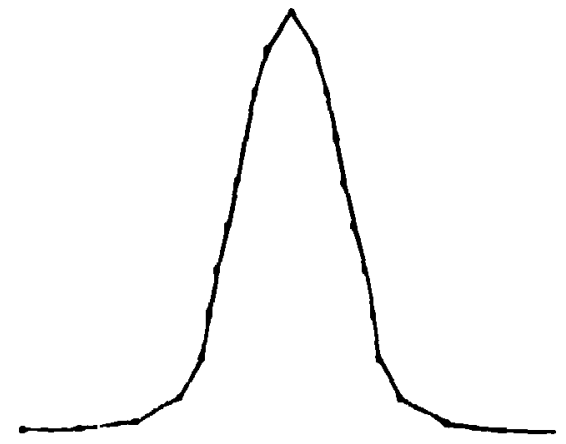

(a)

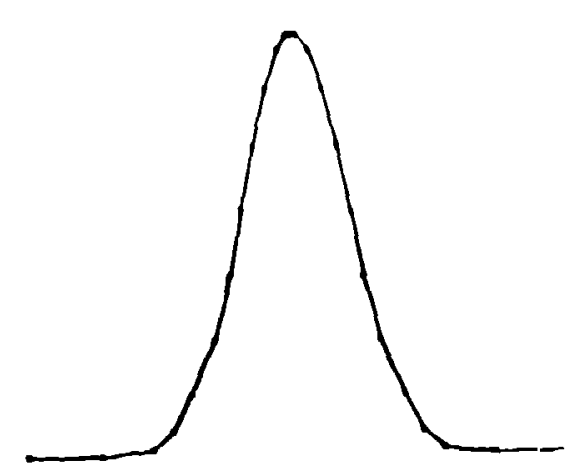

(b)

rly. H. In (a). polnts are equally speced along the curve. In (b), the polnts are roncentratesl in reciluns of $h$ Igh curvalure. 